\title{
ПРИМЕНЕНИЕ СЕЙСМИЧЕСКИХ МЕТОДОВ ДЛЯ ОЦЕНКИ ПЕРСПЕКТИВ НЕФТЕГАЗОНОСНОСТИ ОТЛОЖЕНИЙ ПАЛЕОЗОЙСКОГО ФУНДАМЕНТА ЗАПАДНО-СИБИРСКОЙ ПЛИТЫ
}

\author{
Волкова Александра Александровна', \\ VolkovaAA@hw.tpu.ru \\ Меркулов Виталий Павлович', \\ MerkulovVP@hw.tpu.ru \\ 1 Национальный исследовательский Томский политехнический университет, \\ Россия, 635050, г. Томск, пр. Ленина, 30.
}

Актуальность исследования обусловлена необходимостью увеличения сырьевого потенциала месторождений Западной Сибири, приуроченных к доюрским отложениям, с минимальными затратами на дополнительную разведку. Такая возможность связана с резким развитием технологий сейсмической разведки в последние годы. Современная сейсмическая 3D съёмка позволяет прослеживать характерные особенности геологического строения палеозойских отложений, которые было невозможно различить на профильных сейсмических разрезах 2D. Для получения наиболее объективных результатов целесообразно применение комплекса методов, включающих, помимо сейсморазведки, методы геофизических исследований скважин.

Цель: выделить перспективные участки для освоения доюрского комплекса по данным сейсморазведки на примере одного из месторождений Томской области, приуроченных к палеозойскому фундаменту Западной Сибири.

объекты: отложения палеозойского фундамента юго-восточной части Западно-Сибирской плиты, характеризующиеся сложным вещественным составом горных пород, складчато-блоковым тектоническим строением, наличием естественной трещиноватости карбонатных коллекторов, порово-каверново-трещиным типом коллектора.

Методы: специальный анализ сейсмических атрибутов; сейсмический фациальный анализ; комплексирование сейсмических методов и результатов интерпретации скважинных данных.

Результаты. Выполнен анализ пространственного изменения сейсмических атрибутов, на основе которого выделены зоны повышенной трещиноватости и проведена оценка преобладающего направления систем трещин. Применение сейсмофациального анализа позволило выявить приуроченность участков повышенной плотности трещин к породам с улучшенными коллекторскими свойствами. Построенная схема перспектив нефтегазоносности палеозойских отложений на примере одного из месторождений Западной Сибири удовлетворительно согласуется с результатами геофизических исследований скважин и данными лабораторного изучения керна.

\section{Ключевые слова:}

Доюрский фундамент, палеозой, естественная трещиноватость,

сейсмические методы выделения трещиноватости, комплексирование сейсмических и скважинных данных.

\section{Введение}

Представление о палеозойских отложениях Западной Сибири формировались на протяжении нескольких десятков лет, основы заложены в работах $[1,2]$. Отдельное внимание уделялось изучению тектонического строения региона [3].

В палеозойских отложениях открыто несколько крупных месторождений, но несмотря на высокие перспективы обнаружения залежей углеводородов, проблема изучения особенностей геологического строения этого нефтегазоносного комплекса остается весьма актуальной.

Отложения доюрского комплекса фундамента характеризуются высокой степенью пространственной неоднородности разреза, присутствием пород различного вещественного состава, начиная от терригенных отложений коры выветривания, глинистых, кремнисто-сланцевых пород, песчаников, вулканогенно-осадочных и магматических образований и заканчивая карбонатными породами - известняками и доломитами. Повышенными коллекторскими свойствами могут обладать либо породы коры выветривания (нефтегазоносный горизонт зоны контакта чехла и фундамента НГГЗК), либо трещиноватые разности пород собственно палеозойского возраста, чаще всего пред- ставленные доломитизированными известняками. Палеозойские отложения характеризуются весьма сложным складчато-блоковым строением, вследствие чего в геологических разрезах часто наблюдаются крутые углы падения крыльев складок и высокая раздробленность [1]. Для карбонатных отложений весьма часто проявляется вторичная доломитизация известняков, которые впоследствии становятся трещиноватыми благодаря изменениям в кристаллической решетке, при которых порода становится более хрупкой и подверженной деформациям. Кроме того, образование трещин обуславливается и воздействием горного давления на породы фундамента.

В соответствии с вышесказанным, отложения палеозойского фундамента характеризуются порово-каверново-трещинным типом коллектора, весьма сложным для изучения стандартным комплексом геолого-геофизических методов. С позиций сейсмических исследований палеозойских отложений существует проблема частичного или полного отсутствия субгоризонтальных поверхностей для формирования отраженных волн [4]. Для углубленного изучения палеозойских отложений требуется применение современных методов сейсмической разведки и интегрирование с доступными 
скважинными данными, такими как исследования керна и результаты интерпретации скважинного пластового микросканера.

Нефтяная залежь описываемого в работе месторождения приурочена к доломитам замещения и характеризуется направленной трещиноватостью. Месторождение расположено в юго-восточной части Западно-Сибирской нефтегазоносной провинции в зоне сочленения Нижневартовского антиклинория и Нюрольской впадины. Согласно имеющимся геологическим данным, ловушка углеводородов сформирована в северо-восточном крыле синклинальной складки северо-западного простирания на эрозионно-тектонической террасе фундамента (рис. 1) [5].

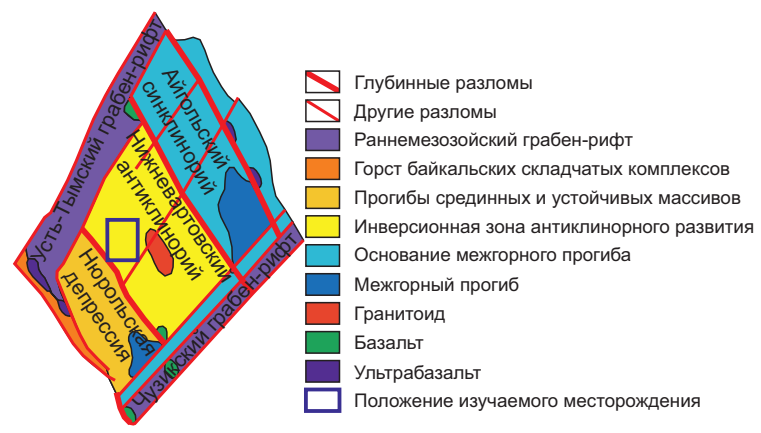

Pис.1. Тектоническая схема изучаемого района (на основе тектонической карты фундалента Западно-Сибирской пли ты Толской области под ред. В.С. Суркова, 1981 г.)

Fig. 1. Tectonic scheme of the studied area (on the basis of the tectonic map of the basement of the West Siberian plate of the Tomsk region, ed.V.S. Surkov, 1981)

Для изучения данного месторождения применялось комплексирование методов сейсмического атрибутного и сейсмофациального анализа со скважинными исследованиями.

\section{Сейсмические методы изучения}

\section{сложнопостроенных трещиноватых коллекторов}

Для изучения трещиноватых коллекторов сейсмическими методами наиболее распространённым из них является специальный анализ сейсмических атрибутов, подчёркивающих особенности волнового поля, связанные с тектоническими особенностями строения изучаемой территории и трещиноватостью горных пород, таких как затухание сигнала, снижение частоты и т. д. [6-9]. Некоторые атрибуты усиливают эффект наличия тектонических нарушений и трещиноватости, образуя так называемые линеаменты, которые можно ассоциировать с разломами и с очагами систем трещин различной направленности $[10,11]$. В каждом частном случае одни атрибуты подчёркивают искомые особенности в большей степени, чем другие.

На примере изучаемого месторождения был проведен анализ сейсмических атрибутов, таких как кривизна, дисперсия, Ant-Tracking, контраст амплитуд и затухание амплитуды со временем.
Атрибут кривизны является структурным атрибутом и показывает, как в конкретной точке изменяется конфигурация отражающего горизонта. Судя по литературным источникам $[6,12]$, зоны с повышенной кривизной связаны участками повышенной трещиноватости горных пород. Дисперсия оценивает степень отличия соседних сейсмотрасс, при повышенной дисперсии можно предполагать наличие разломов или скопление трещин. В атрибут Ant-Tracking заложены принципы искусственного интеллекта для улучшенной прослеживаемости разломов и зон с повышенной направленной трещиноватостью. Высокий контраст амплитуд, так же как и затухание амплитуды со временем, характеризует зоны повышенной трещиноватости.

Для палеозойского фундамента изучаемого месторождения атрибут Ant-Tracking, pacсчитанный по атрибуту дисперсии для усиления искомых особенностей сигнала, показал наиболее удовлетворительные результаты. Картина, ассоциируемая с трещиноватостью, отличается наиболее высокой степенью разрешенности по сравнению с остальными рассмотренными атрибутами. Карта атрибута Ant-Tracking по изучаемому объекту представлена на рис. 2. Особенностью представленной картины является четко фиксируемая система линеаментов преимущественно северо-западного и северо-восточного простирания, хорошо согласующаяся с современными представлениями о пространственном расположении и ориентации основных тектонических нарушений и систем трещин в палеозойских отложениях [1].

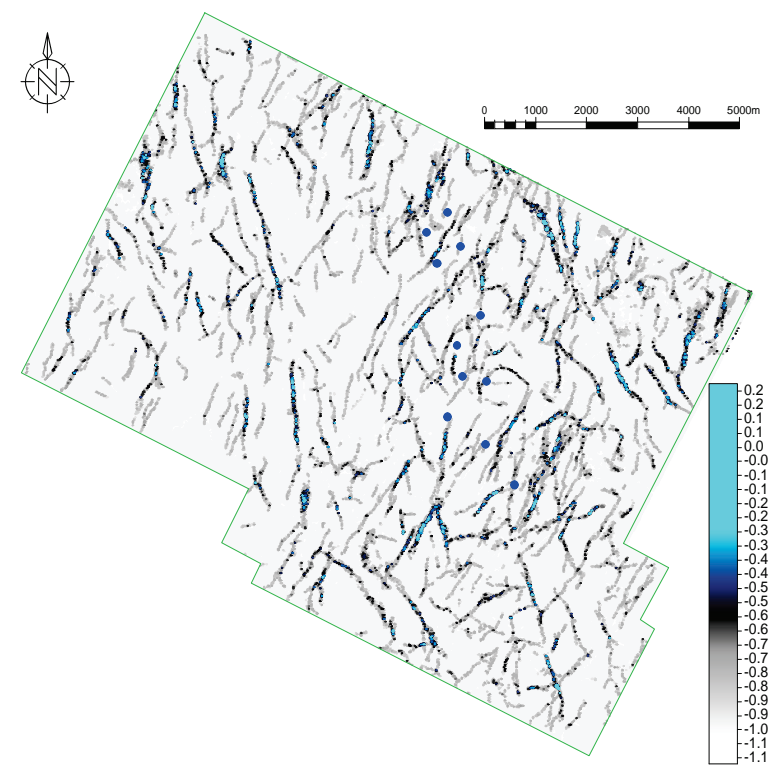

Puc. 2. Сейсмический атрибут Ant-Tracking

Fig. 2. Seismic attribute Ant-Tracking

Следующим этапом после анализа сейсмических атрибутов является оценка плотности трещиноватости и преимущественной направленности трещин. Выбранный ранее эффективный атрибут Ant-Tracking был применен для решения предложенных задач. 
Для расчета карты относительной плотности трещиноватости была использована суммарная длина линеаментов атрибута Ant-Tracking на единицу площади. Для удобства восприятия значения плотности трещиноватости были нормированы на размах вычисленных показаний, в этом случае максимальная трещиноватость характеризуется значениями, близкими к единице, а минимальная трещиноватость, либо её отсутствие - значениями около нуля (рис. 3). Анализ полученной схемы распределения нормированной плотности трещиноватости показывает, что наибольшие показатели трещиноватости локализованы в южной и северовосточной частях площади исследований. Продуктивные скважины приурочены к зонам высокой и средней плотности трещин.

Для оценки преимущественных направлений трещиноватости площадь месторождения была разбита на несколько десятков блоков. Длина стороны блока выбиралась исходя их попадания в блок статистически достаточного числа линеаментов (которые были описаны в работе выше). Проведенный анализ атрибута Ant-Tracking позволил получить розы-диаграммы направленности линеаментов, которые ассоциируются с направленностью систем трещин (рис. 4, В).

Адекватность построенных роз-диаграмм подтверждается результатами интерпретации исследований пластовым электрическим микросканером (рис. 4, А) скважины, местоположение которой выделено на рис. 3 красным цветом. Наблюдается достаточно хорошая согласованность данных по пространственной ориентации систем трещин, полученных по результатам микросканирования и специального анализа сейсмических данных в области исследуемой скважины. Соответственно, применение атрибута Ant-Tracking для решения задач оценки преимущественных направлений трещиноватости следует считать целесообразным [13].

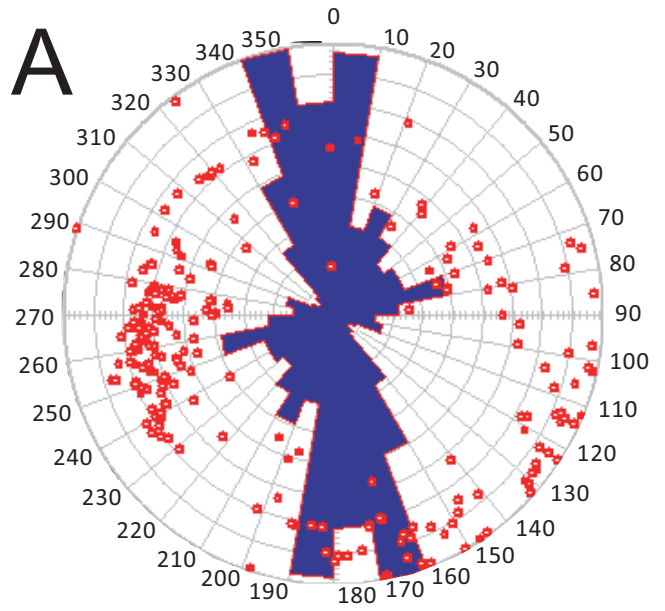

- Угол падения трещин

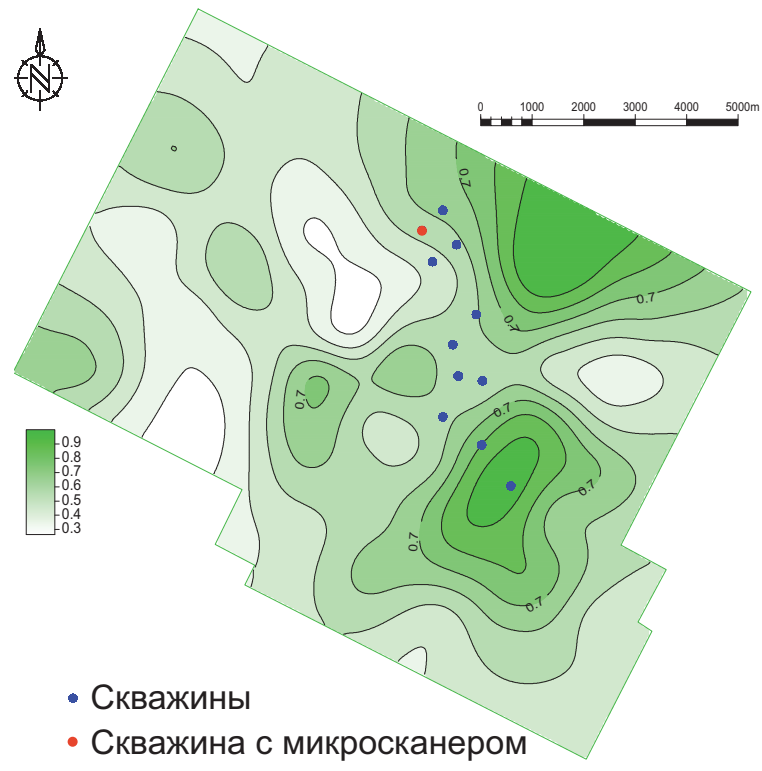

Рис.3. Карта плотности трещиноватости

Fig. 3. Fracture density map

В связи со сложным вещественным составом палеозойских пород изучаемого месторождения применения сейсмического атрибутного анализа для оценки только трещиноватости недостаточно при решении задач локального нефтепрогноза. Следует классифицировать волновое сейсмическое поле на зоны, характеризующие различный литологический состав пород палеозойского фундамента [14]. При этом обязательно должны быть выделены группы пород, обладающие улучшенными фильтрационно-емкостными свойствами и относящиеся к понятию «коллектор». Учитывая каверново-трещинный тип пустотного пространства палеозойских отложений, зоны, определенные как коллектор с точки зрения литологического состава пород и характеризующиеся повышенной трещи-

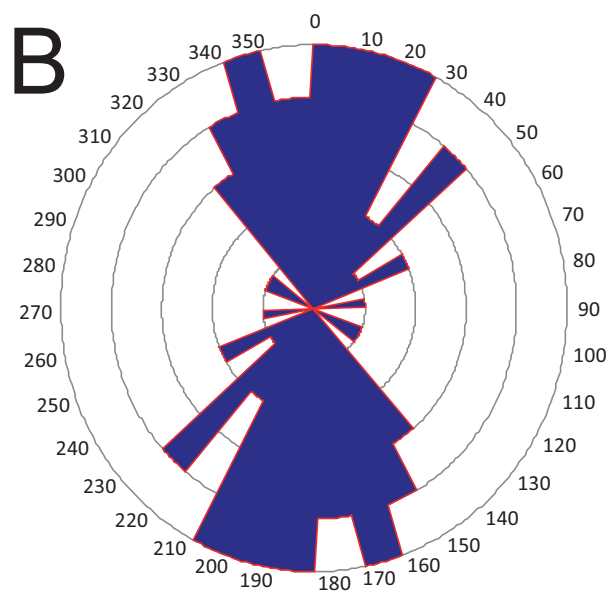

\section{Азимут падения трещин}

Puс. 4. Направления трещиноватости, выделенные пластовым микросканером (A), и по сейслическому атрибуту Ant-Tracking (B) в области расположения скважины, в которой проводились исследования пластовыл микросканером

Fig. 4. Natural fracture orientation by formation microimager (left) and by seismic attribute Ant-Tracking (right) in the area of the well with formation microimager survey 
новатостью, могут быть приняты как прогнозные области вероятных ловушек углеводородов.

Сейсмофациальный анализ был применён с целью выделения зон коллекторов, которые сложены в случае изучаемого месторождения доломитами замещения, развитыми по известнякам. Были выбраны шесть сейсмических атрибутов, применяющихся при анализе коллекторов, которые позволяют оконтурить зоны с переменными характеристиками волнового поля, идентифицировать геологические объекты и выделить аномальные зоны. Далее была проведена классификация волнового поля атрибутов в пределах кровли палеозойского фундамента методом искусственных нейронных сетей [15-20].

Использованы следующие атрибуты: среднеквадратичная амплитуда, относительный акустический импеданс, мгновенная частота, мгновенная фаза, мгновенное качество, первая производная и затухание амплитуды со временем.

Методы сейсмического фациального анализа позволяют классифицировать сейсмическое волновое поле по характерным признакам на заданное количество групп. Скважины с керновым материалом представлены четырьмя основными литологическими разностями, такими как доломиты (породы, характеризующиеся улучшенными коллекторскими свойствами, известняки (возможные коллекторы), кремнистые породы (неколлектор) и эффузивные породы (неколлектор). Классификация на три сейсмических класса демонстрирует результаты, которые наилучшим образом согласуются с геологической информацией. Схема результата сейсмофациального анализа с наложенными керновыми данными по литологии представлена на рис. 5. Для изучаемого месторождения было принято решение объединить литологию пород, определённых по керну, не являющихся коллектоpoм, в один класс. В итоге сейсмический класс 1 (фиолетового цвета) показывает наилучшую сходимость со скважинами, керновые материалы которых представлены доломитом, сейсмический класс 2 (голубого цвета) ассоциируется с известняком и сейсмический класс 3 (синего цвета) - с породами неколлекторами.

Жёлтыми полигонами на рис. 5 показаны зоны деструкции палеозойского фундамента по комплексу геолого-геофизических данных, синими линиями - условные границы блоков доюрского основания по данным корреляционного метода преломленных волн (КМПВ) и гравимагниторазведки, и чёрными линиями представлены изогипсы кровли палеозойского фундамента.

Комплексная интерпретация специального сейсмического атрибутного анализа и сейсмофациального анализа позволила выделить перспективные участки отложений палеозойского фундамента на месторождении, которые рекомендуются для дальнейшего освоения [7, 13, 21]. Выделенные перспективные зоны характеризуются повышенной плотностью трещиноватости и сейсмическим фациальным классом, ассоциируемым с коллектором - доломитами замещения.

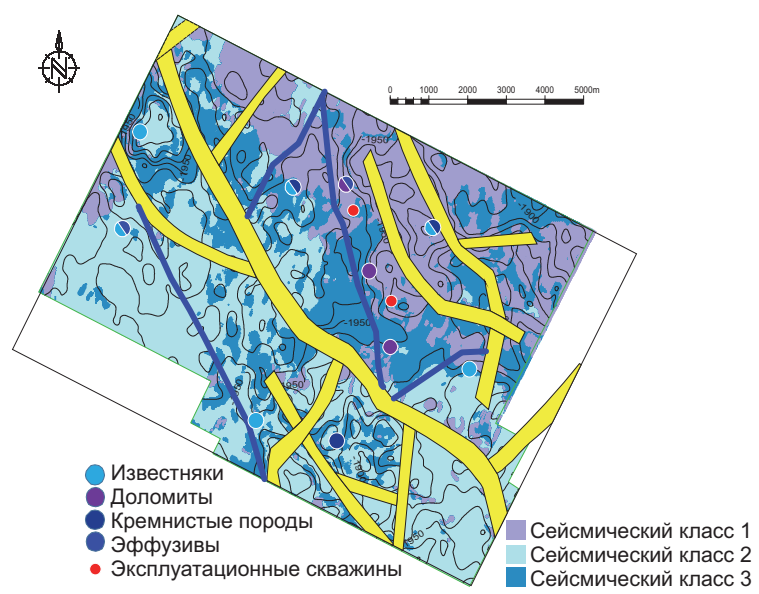

Pис. 5. Результат сейсмофациального анализа с наложенныли данными по литологии керна

Fig. 5. Seismic facies analysis result with overlaid core lithology

Схема перспективности палеозойских отложений представлена на рис. 6. Повышенная трещиноватость показана зелёной штриховкой, а сейсмический класс коллектора - коричневой штриховкой. Зона объединения двух характерных признаков является перспективной. Для того чтобы при планировании бурения новых скважин учесть преимущественные направления трещиноватости и вскрыть максимальное количество трещин, на рисунке также отображены розы-диаграммы прогнозных преимущественных направлений трещиноватости в пределах оконтуренного перспективного участка.

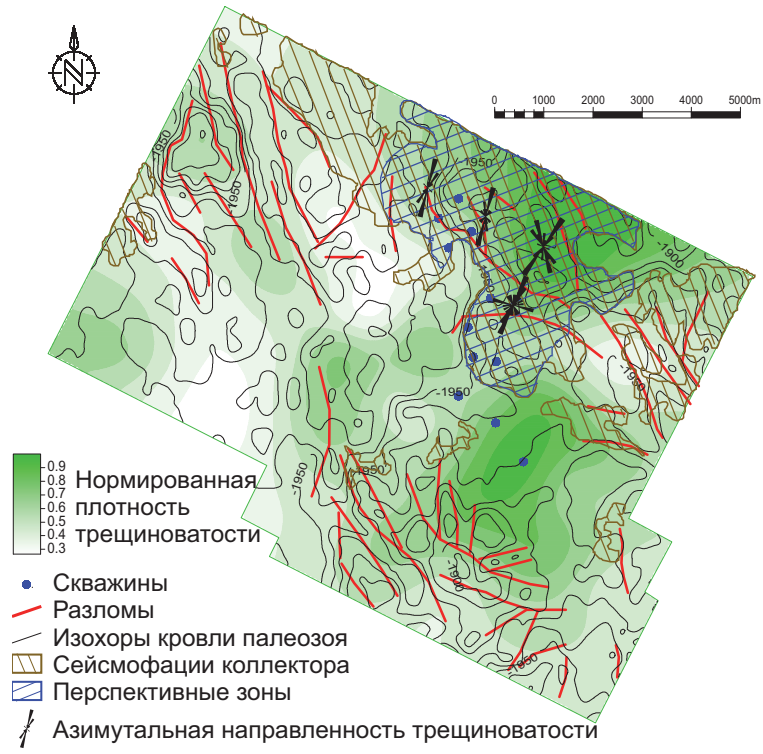

Puc. 6. Схема перспективности палеозойских отложений в пределах изучаемого месторождения

Fig. 6. Paleozoic perspective areas scheme within the studied field 


\section{Заключение}

Комплексный подход к изучению месторождения в палеозойском фундаменте Западной Сибири современными сейсмическими методами, такими как специальный сейсмический атрибутный анализ для оценки плотности и направленности трещиноватости и сейсмофациальный анализ для определения зоны с преобладанием коллектора, с учётом доступной информации по скважинным данным, позволил оконтурить перспективные участки на одном из месторождений Западной Сибири.

\section{СПИСОК ЛИТЕРАТУРЫ}

1. Жеро О.Г., Смирнов Л.В., Сурков В.С. 0 перспективах нефтегазоносности доюрского фундамента Западно-Сибирской плиты // Геология и геофизика - 1968. - № II. - С. 3-11.

2. Исаев Г.Д. Фациальные модели девона Нюрольской зоны и основные критерии районирования палеозоя Западно-Сибирской плиты // Литосфера - 2011. - № 6. - С. 27-37.

3. Белоусов В.В. Основы геотектоники. - М.: Недра, 1989. $382 \mathrm{c.}$

4. Волкова А.А., Меркулов В.П. Информативность 3D сейсморазведки при оценке перспектив нефтегазоносности отложений Палеозойского фундамента Западной Сибири // 8-ая международная геолого-геофизическая конференция и выставка «Санкт-Петербург 2018» EAGE. Тезисы доклада. - СПб., 2018. URL: earthdoc.eage.org/publication/publicationdetails/?publication $=91397$ (дата обращения 10.10.2018).

5. Ежова А.В., Меркулов В.П., Чеканцев В.А. Геологическая модель строения палеозойского фундамента Северо-Останинского нефтяного месторождения (Томская область) // Горный журнал. - 2012. - Специальный выпуск. - С. 35-38.

6. Chopra S., Marfurt K. Seismic Attributes for Prospect Identification and Reservoir Characterization // Geophysical Developments. - Tulsa: SEG, 2007. - 464 p.

7. Seismic to simulation fracture characterization of a Green carbonate reservoir in presence of large uncertainties / D. Astratti, L. Souche, M. Faskhoodi, P. Menegatti // SPE Abu Dhabi International Petroleum Exhibition \& Conference. - Abu Dhabi, 2010. URL: https:/ /doi.org/10.2118/136829-MS (дата обращения 10.10.2018).

8. Godfrey R., Bachrach R. Seismic guided fracture characterization // CSEG Recorder. - 2008. - V. 1. - P. 30-36.

9. Lewis H., Hall S. Geomechanics-seismic links for fracture identification // EAGE/SEG research workshop. Expanded Abstracts. Perugia, 2007. URL: earthdoc.eage.org/publication/publicationdetails/?publication=7729 (дата обращения 10.10.2018).

10. Yan L., Ochoa J. Quantitative Seismic Fracture Characterization Using Azimuthal Anisotropy from WAZ 3D: Case Studies from USA Onshore Ba $/ / 80^{\text {th }}$ EAGE Annual Conference and Exhibition. Expanded Abstracts. - Copenhagen, 2018. URL: earthdoc.eage.org/publication/publicationdetails/?publication=92452 (дата обращения 10.10.2018).

11. Seismic detection of subtle faults and fractures / V. Aare, D. Astratti, T. Dayyni, S. Mahmoud, A. Clark, M. Stellas, J. Stringer, B. Toelle, 0. Vejbaek, G. White // Oilfield review. - 2012. V. 24. - № 2. - P. 28-43.

12. Characterizing fracture corridors for a large carbonate field of Kuwait by integrating borehole data with the 3-D surface seismic
На перспективном участке была выделена направленная трещиноватость преимущественно в север-северо-восточном направлении, что является ключевым фактором при выборе оптимального направления заложения горизонтальных скважин.

Предлагаемая в работе методика комплексирования сейсмических методов и скважинных данных в месторождениях палеозойского фундамента Западной Сибири с трещиноватым типом коллектора рекомендуется к опробованию на соседних месторождениях со схожим строением.

S. Singh, M. Akbar, B. Khan, H. Abu-Habbiel, B. Montaron, L. Sonneland, R. Godfrey // AAPG convention. - Denver, 2009. URL: www.searchanddiscovery.com/pdfz/documents/2009/ 40464singh/ndx singh.pdf.html (дата обращения 10.10.2018).

13. An integrated approach for fracture characterization and prediction using FMI logs, post-stack seismic attributes and pre-stack anisotropy - a case study in Tishrine West oilfield / J. Yang, X. Gou, N. Hilmi, R. Xia, X. Sun, P. Li, Q. Wu, H. Liu // SEG San Antonio 2011 Annual Meeting. - San Antonio, 2011. - P. 1814-1818. URL: https://doi.org/10.1190/1.3627558 (дата обращения 10.10.2018).

14. Пейтон Ч. Сейсмостратиграфия. - М.: Мир, 1982. - 374 с.

15. Белов Р.В., Кондрашов В.А., Мельников В.П. Опыт комплексного сейсмофациального анализа данных МОГТ и КМПВ // Геология нефти и газа. -1990 . - № 3. - С. 33-36.

16. Сейсмофациальный анализ и возможности прогнозирования литотипов пород по данным сейсморазведки / Г.Д. Ухлова, В.В. Соломатин, Л.И. Штифанова, Т.И. Чернышова // VII Всероссийское литологическое совещание. - Новосибирск, 2013. - С. 227-230.

17. Seismic facies analysis and structural interpretation of the Sandakan sub-basin / K. Futalan, A. Mitchell, K. Amos, G. Backe // AAPG international conference and exhibition. - Singapore, 2012. URL: www.searchanddiscovery.com/documents/2012/ 30254futalan/ndx_futalan.pdf (дата обращения 10.10.2018).

18. Saggaf M., Nafi Toksoz M., Mahroon M. Seismic facies classification and identification by competitive neural networks // Geophysics. - 2003. - V. 68. - № 6. - P. 1984-1999.

19. Волкова А.А. Применение сейсмофациального анализа для уточнения схемы геологического строения на примере месторождения в фундаменте Западной Сибири / / Современные проблемы седиментологии в нефтегазовом инжиниринге: Труды III Всероссийского научно-практического седиментологического совещания. - Томск, 2017. - С. 223-228.

20. Волкова А.А. Выбор оптимальных параметров сейсмического фациального анализа при изучении палеозойских отложений Западной Сибири // Проблемы геологии и освоения недр: Труды XXII Международного научного симпозиума имени академика М.А. Усова студентов и молодых ученых. - Томск: ТПУ, 2018. - T. I. - C. 383-384.

21. Волкова А.А. Комплексный анализ сейсмических и скважинных данных при изучении трещиноватых коллекторов на примере месторождения в фундаменте Западной Сибири // Проблемы геологии и освоения недр: Труды XXI Международного научного симпозиума имени академика М.А. Усова студентов и молодых ученых. - Томск: ТПУ, 2017. - Т. І. - С. 356-358.

Поступила 17.10.2018 г.

\section{Информация об авторах}

Волкова $\boldsymbol{A} . \boldsymbol{A}$., аспирантка, инженер лаборатории месторождений нефти и газа Инженерной школы природных ресурсов Национального исследовательского Томского политехнического университета.

Меркулов В.П., кандидат геолого-минералогических наук, ведущий эксперт Инженерной школы природных ресурсов Национального исследовательского Томского политехнического университета. 
UDC 550.834 .05

\title{
APPLICATION OF SEISMIC METHODS FOR ESTIMATING THE PERSPECTIVE OF OIL AND GAS POTENTIAL OF THE SEDIMENTS OF THE PALEOZOIC BASEMENT OF THE WESTERN SIBERIAN PLATE
}

\author{
Aleksandra A. Volkova', \\ VolkovaAA@hw.tpu.ru

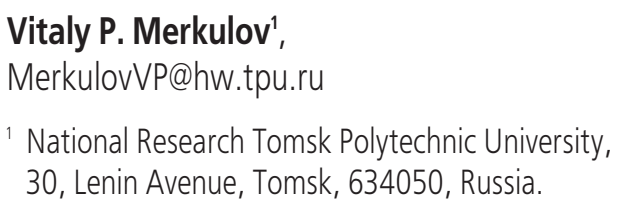

The relevance of the research is caused by the need to increase the raw potential of fields in Western Siberia, confined to pre-Jurassic deposits, with minimal additional exploration costs. This possibility is associated with the dramatic development of seismic survey technology in recent years. Modern 3D seismic survey allows tracing the characteristic features of the geological structure of the Paleozoic deposits, which were impossible to distinguish on 2D profile seismic sections. To obtain the most objective results, it is advisable to use a set of methods that include, in addition to seismic prospecting, methods of well logging.

The main aim of the research is to identify promising areas for development of the pre-Jurassic complex according to seismic data on the example of one of the fields in Tomsk region, confined to the Paleozoic basement of Western Siberia.

objects of research are deposits of the Paleozoic basement of the southeastern part of the West Siberian Plate, characterized by a complex material composition of rocks, a folded-block tectonic structure, the presence of natural fracturing of carbonate reservoirs, and porous-vuggy-fractured reservoir rock.

Methods: seismic attribute analysis, seismic facies analysis, integration of seismic and results of well data interpretation.

Results. The authors have carried out the analysis of spatial changes in seismic attributes, on the basis of which zones of increased fracturing were identified and the prevailing direction of fracture systems was assessed. The use of seismic facies analysis allowed identifying the confinement of areas of increased density of fractures to rocks with improved reservoir properties. The scheme developed for the oil and gas potential of the Paleozoic deposits on the example of one of the fields in Western Siberia is in satisfactory agreement with the results of geophysical well studies and data from a laboratory core study.

\section{Key words:}

Pre-Jurassic basement, Paleozoic, natural fracturing, seismic fracture extraction methods, seismic and well data integration.

\section{REFERENCES}

1. Jero 0.G., Smirnov L.V., Surkov V.S. o perspektivakh neftegazonosnosti doyurskogo fundamenta Zapadno-Sibirskoy plity [On the prospects for the oil and gas content of the pre-Jurassic basement of the West Siberian plate]. Russian Geology and Geophysics, 1968, no. II, pp. 3-11.

2. Isaev G.D. Devonian facial models of the Nyurol zone and the main criteria for the regional division of the Paleozoic of the West Siberian Plate. Lithosphere, 2011, no. 6, pp. 27-37. In Rus.

3. Belousov V.V. Osnovy geotektoniki [Geotectonics basics]. Moscow, Nedra Publ., 1989. 382 p.

4. Volkova A.A., Merkulov V.P. Informativnost 3D seysmorazvedki pri otsenke perspektiv neftegazonosnosti otlozheny Paleozoyskogo fundamenta Zapadnoy Sibiri [Information value of 3D seismic in evaluation the prospects of oil and gas fields of the Paleozoic basement of Western Siberia]. 8 Mezhdunarodnaya geologo-fizicheskaya konferentsiya $i$ vystavka «Sankt Peterburg-2018" [ $8^{\text {th }}$ EAGE Saint Petersburg International Conference and Exhibition. Extended abstract]. St-Petersburg, 2018. Available at: earthdoc.eage.org/publication/publicationdetails/?publication=91397 (accessed 10 October 2018).

5. Ezhova A.V., Merkulov V.P., Chekantsev V.A. Paleozoic basement geological structure model of Northern Ostaninsk oil field (Tomsk region). Mountain Journal, 2012, Special issue, pp.35-38. In Rus.

6. Chopra S., Marfurt K. Seismic Attributes for Prospect Identification and Reservoir Characterization. Geophysical Developments. Tulsa, SEG, 2007. 464 p.

7. Astratti D., Souche L., Faskhoodi M., Menegatti P. Seismic to simulation fracture characterization of a Green carbonate reservoir in presence of large uncertainties. SPE Abu Dhabi International
Petroleum Exhibition \& Conference. Abu Dhabi, 2010. Available at: https://doi.org/10.2118/136829-MS (accessed 10 October 2018).

8. Godfrey R., Bachrach R. Seismic guided fracture characterization. CSEG Recorder, 2008, vol. 1, p. 30-36.

9. Lewis H., Hall S. Geomechanics-seismic links for fracture identification. $E A G E / S E G$ research workshop. Expanded Abstracts. Perugia, 2007. Available at: earthdoc.eage.org/publication/publicationdetails $/$ ? publication $=7729$ (accessed 10 October 2018).

10. Yan L., Ochoa J. Quantitative Seismic Fracture Characterization Using Azimuthal Anisotropy from WAZ 3D: Case Studies from USA Onshore Ba. 80 th EAGE Annual Conference and Exhibition. Expanded Abstracts. Copenhagen, 2018. Available at: earthdoc.eage.org/publication/publicationdetails/?publication $=92452$ (accessed 10 October 2018).

11. Aare V., Astratti D., Dayyni T., Mahmoud S., Clark A., Stellas M., Stringer J., Toelle B., Vejbaek O., White G. Seismic detection of subtle faults and fractures. Oilfield review, 2012, vol. 24, no. 2 , pp. $28-43$.

12. Singh S., Akbar M., Khan B., Abu-Habbiel H., Montaron B., Sonneland L., Godfrey R. Characterizing fracture corridors for a large carbonate field of Kuwait by integrating borehole data with the 3-D surface seismic. AAPG convention. Denver, 2009. Available at: www.searchanddiscovery.com/pdfz/documents/2009/ 40464singh/ndx_singh.pdf.html (accessed 10 0ctober 2018).

13. Yang J. Gou X., Hilmi N., Xia R., Sun X., Li P., Wu Q., Liu H. An integrated approach for fracture characterization and prediction using FMI logs, post-stack seismic attributes and pre-stack anisotropy - a case study in Tishrine West oilfield. SEG San Antonio 2011 Annual Meeting. San Antonio, 2011. pp. 1814-1818. Available at: https://doi.org/10.1190/1.3627558 (accessed 10 October 2018). 
14. Peyton Ch. Seismostratigrafiya [Seismic stratigraphy]. Moscow, Mir Publ., 1982. 374 p.

15. Belov R.V., Kondrashov V.A., Melnikov V.P. Opyt kompleksnogo seysmofatsialnogo analiza dannykh MOGT i KMPV [Experience in complex seismic facies data analysis of CDP and KMPV]. Oil and gas geology, 1990, no. 3, p. 33-36.

16. Ukhlova G.D., Solomatin V.V., Shtifanova L.I., Chernishova T.I. Seismofatsialniy analiz i vozmozhnosti prognozipovaniya litotipov porod po dannym seysmorazvedki [Seismic facies analysis and forecasting capabilities of rock lithotypes according to seismic data]. VII Vserossiyskoe litologicheskoe soveshchanie [VII AllRussian Lithological Meeting]. Novosibirsk, 2013. p. 227-230.

17. Futalan K., Mitchell A., Amos K., Backe G. Seismic facies analysis and structural interpretation of the Sandakan sub-basin. $A A P G$ international conference and exhibition. Singapore, 2012. Available at: www.searchanddiscovery.com/documents/2012/ 30254futalan/ndx_futalan.pdf (accessed 10 0ctober 2018).

18. Saggaf M., Nafi Toksoz M., Mahroon M. Seismic facies classification and identification by competitive neural networks. Geophysics, 2003, vol. 68, no. 6, pp. 1984-1999.

19. Volkova A.A. Primenenie seismofatsialnogo analiza dlya utochneniya skhemy geologicheskogo stroeniya na primere mestorozgdeniya $v$ fundamente Zanadnoy Sibiri [Use of seismic facies analysis to clarify the geological structure of the field as an example in the basement of Western Siberia]. Sovremennye problemy sedimentologii v neftegazovom inzhiniringe. Trudy III vse rossiyskogo nauchno-prakticheskogo sedimentilogicheskogo so- veshchaniya [Modern problems of sedimentology in oil and gas engineering. Proc. of the III All-Russian Scientific and Practical Sedimentology Meeting]. Tomsk, 2017. pp. 223-228.

20. Volkova A.A. Vybor optimalnykh parametrov seysmicheskogo fatsialnogo analiza pri izuchenii paleozoiskikh otlozheniy Zapadnoy Sibiri [Selection of optimal parameters of seismic facies analysis in the study of Paleozoic deposits in Western Siberia]. Problemy geologii $i$ osvoeniya nedr. Trudi XXII Mezhdunarodnogo nauchnogo simpoziuma imeni akademika M.A. Usova studentov $i$ molodykh uchenykh [Problems of geology and subsoil development. Proc. of the XXII International Scientific Symposium named after Academician M.A. Usov students and young scientists]. Tomsk, TPU, 2018. Vol. I, pp. 383-384.

21. Volkova A.A. Kompleksniy analiz seismicheskikh i skvazginnykh dannykh pri izuchenii treshchinovatykh kollektorov na primere mestorozhdeniya $\mathrm{v}$ fundamente Zapadnoy Sibiri [Comprehensive analysis of seismic and well data in the study of fractured reservoirs on the example of a field in the basement of Western Siberia]. Problemy geologii i osvoeniya nedr. Trudi XXII Mezhdunarodnogo nauchnogo simpoziuma imeni akademika M.A. Usova studentov i molodykh uchenykh [Problems of geology and subsoil development. Proc. of the XXI International Scientific Symposium named after Academician M.A. Usov students and young scientists]. Tomsk, TPU, 2018. Vol. I, pp. 356-358.

Received: 17 October 2018.

\section{Information about the authors}

Aleksandra A. Volkova, postgraduate student, reservoir engineer, National Research Tomsk Polytechnic University.

Vitaly P. Merkulov, Cand. Sc., leading expert, National Research Tomsk Polytechnic University. 